\title{
Extreme Rainfall Return Periods using Gumbel and Gamma Distribution
}

\author{
K. Sasireka, C.R. Suribabu, T.R. Neelakantan
}

\begin{abstract}
Extreme rainfall amount at various return periods is one of the key inputs in the design of various hydraulic structures. In order to reduce damages that may arise due to extreme rainfall, it is very important to estimate accurately by a suitable probability distribution. Gumbel and Gamma distributions are widely applied to fit the extreme rainfall events. In the present work, an attempt is made to find maximum rainfall that could occur at various return periods, (10, 20, 50, 75, 100 and 200 years) for Tiruchirappalli city located in India. The rainfall data starting from the year 1904 to 2010 is used to predict extreme rainfall. Akaike Information Criteria (AIC) and Bayesian information criteria (BIC) were employed to determine the best probability distribution for rainfall data belongs to Tiruchirappalli station.
\end{abstract}

Keywords : Extreme rainfall, hydraulic structures, probability distribution

\section{INTRODUCTION}

Extreme rainfall events cause severe damages to the Civil and Electrical Engineering infrastructures apart from agricultural activities and loss of life. Frequency analysis (FA) is considered as an important aspect of hydrology, which uses the past records to deduce the future probabilities of occurrence of hydrological events. By using probability distribution, FA relates magnitude of the event with its frequency of occurrence of the extreme events. In FA, an hourly, daily, seasonal, or annual observation of hydrological variables has been used for prediction of extreme event. The different forms of hydrological data used for FA are: Complete Duration Series (CDS) in which all the records of daily, monthly or annual data considered for analysis.

A data series consisting of the largest or smallest annual values is termed as Annual Maximum (or minimum) Series (AMS). It is very important to carry out frequency analysis of extreme events for better decision making to manage water resources. The Prime objective of the FA is to establish the relationship between the magnitude of extreme events and their frequency of occurrence using appropriate probability distributions [1]. Many study focused general aspect of frequency analysis: Bobee and Ashhar [2], McCuen [3], and Stedinger et al. [4]. Guhathakutra et al.,[5] and carried out the frequency analysis of rainy days, heavy rainfall days and also one-day extreme rainfall to ascertain any change in the

Revised Manuscript Received on December 05, 2019.

* Correspondence Author

K. Sasireka, School of Civil Engineering, SASTRA Deemed University, Thanjavur-613 401, India, sasireka@ civil.sastra.edu

C.R. Suribabu, School of Civil Engineering, SASTRA Deemed University, Thanjavur - 613 401, India, suribabu@ civil.sastra.edu

T.R. Neelakantan*, Department of Civil Engineering, Kalasalingam Academy of Research and Education, Krishnankoil 626126, India, neelakantan@klu.ac.in

regional climate change or impact of climatic changes on extreme weather condition of drought and flood risks in India. Khan et al., [6] investigated daily and weekly rainfall extremes in South America to determine the spatial and temporal variability.

In the present work, Complete Duration Series (CDS) is used to spot the frequency of extreme rainfall for Tiruchirappalli located in India is determined using Gumbel and Gamma distributions. An estimate is made for 10, 20, 30, $50,75,100$ and 200 years return period for one day, two-day, three-day, four-day and five-day rainfall data. AIC and BIC methods are used to ascertain the best fit distribution for case study data.

\section{GUMBEL DISTRIBUTION}

In water resource engineering, extreme value of rainfall, flood etc., which occur rarely has been considered as a important design parameter for water resource project. This is particularly true when considering the natural hazards like maximum flood levels in the life span of a bridge. Hence, for safe hydrological design the initial step to analyze the hydrological data by choosing the best frequency distribution method. Among other distribution methods, the most often method used for modeling of an annual rainfall series is the Gumbel distribution (GD) method. Common distribution method known as Gumbel distribution, which is also known as the type 1 extreme value distribution, has been applied to the analysis of rainfall extremes values (Gumbel, [7]; Koutsoyiannis, [8]). It is used for the probability distribution of extreme value in hydrologic studies for prediction of flood peak, maximum rainfall, etc. Wilks [9] indicated that the GD underestimates the extreme rainfall amounts. Sheng Yue [10] used Gumbel mixed model to analyze the joint distribution of correlated maximum rainfall intensity.

This distribution results from the underlying assumption that the elements of a random sample follow an exponential distribution. The cumulative distribution function for the exponential distribution is shown below.

$$
F(x)=1-e^{-\lambda x}
$$

Then from the marginal distribution for the maximum value of the random sample which equals to

$$
F x_{\max }(x)=[F(x)]^{n}
$$

which results in,

$$
F x_{\max }(x)=\left[1-e^{-\lambda x}\right]^{n}
$$


Upon the introduction of the location and scale parameters $b$ and a,

$$
F x_{\max }(x)=\left[1-\frac{1}{n} e^{\frac{x-b}{a}}\right]^{n}
$$

As $\mathrm{n}$ tends to infinity it becomes,

$$
F x_{\max }(x)=\exp \left[e^{-\frac{x-b}{a}}\right]
$$

The corresponding probability density function would be

$$
F x_{\max }(x)=\frac{1}{a} \exp \left[-\frac{x-a}{a} e^{-\frac{x-b}{a}}\right] \text { for }-\propto<x<+\propto
$$

If any random variable $\mathrm{X}$ follows Weibull distribution then the $\log X$ follows type 1 extreme value distribution known as the Gumbel distribution.

\section{GAMMA DISTRIBUTION}

Gamma distribution has several applications in many engineering fields; one of the applications in civil engineering is in rainfall modelling. In general, hydrological variables are of the continuous type, they are discretized and used as a discrete series. It is usually assumed that a hydrological variable has a certain distribution type. The distribution methods such as Normal, Log-normal, Gamma, Gumbel, and Weibull are considered as a common method used in hydrological frequency analysis. The normal and log-normal distributions generally fit the annual flows of rivers. It is to be noted that rainfall and runoff are always positive value and the gamma distribution has a merit of having only positive values [11]. Use of Gumbel and Weibull distributions for extreme values either maxima or minima of hydrological variables are very common. The Gumbel distribution is commonly adopted in the frequency analysis of floods (Gumbel,[7]) and the Weibull distribution find its place in the analysis of low flow observed in rivers (Bulu and Aksoy, [12]). Yevjevich [13] presented very detailed information about Gamma distribution. Among different type of Gamma distribution function, 2- and 3- parameter Gamma distribution functions are generally used for frequency analysis compared to 1-parameter Gamma distribution function. It is rarely adopted 1- parameter Gamma distribution function in fitting to frequency distributions of extreme events due to its inflexibility condition. The Gamma distribution was also found to be best one in case of monthly rainfall of arid regions (Sen and Eljadid, [14]). It is general considered that the Gamma distribution is a good choice for rainfall data for several reasons. Since left tail of distribution is bounded zero, Gamma distribution is considered as best distribution for precipitation data (Thom, [15]; Wilks, [16]).

The cumulativee probability using Gamma distribution is found as follows:

$$
G(x)=\frac{1}{\beta^{\alpha} \tau(\alpha)} \int_{0}^{x} x^{\alpha-1} e^{-x / \beta} d x \quad \text { for } x>0
$$

where $\alpha$ - the shape parameter, $\beta$ - the scale parameter, $\mathrm{x}$ - the precipitation value and $\tau(\alpha)$ - Gamma function.

\section{AIC AND BIC ESTIMATORS}

Akaike Information Criteria (AIC) and Bayesian Information Criteria (BIC) are the two estimators available to assess the relative quality of the various statistical models for a given set of information. Both the criterions are very similar in the form, but BIC varies in terms of penalty assigned for the number of parameters. Basically, AIC follows information theory, whereas BIC adopt asymptotic approximation. In the present study, Gumbel and Gamma distributions are used to evaluate rainfall amount for different return periods. Using both AIC and BIC methods, best fitting model was identified for rainfall of the study area. Model having least value of either AIC or BIC is considered as best model.

The AIC is expressed as $A I C=-2 \ln (L)+2 k$ in which $\mathrm{k}$ is the number of model parameters and $\ln (L)$ is the log-likelihood function for the statistical model. With the second order correction AIC is defined as follows for smaller data sets as follows:

$$
A I C_{c}=A I C+\frac{2 k(k+1)}{N-k-1}=\frac{2 N k}{N-k-1}-2 \ln (L)
$$

where $\mathrm{N}$ is the data sample size. The BIC is defined as:

$$
B I C=\ln (N) k-2 \ln (L)
$$

\section{STUDY AREA}

The area taken into consideration for the study is Tiruchirapalli city, which is situated in central south-eastern India, nearly at the geographic centre of the state of Tamil $\mathrm{Nadu}$ has a latitude and longitude of $10.7905^{\circ} \mathrm{N}$ and $78.7047^{0} \mathrm{E}$ respectively. It is one of the most fertile regions of the state. The rain gauge situated at the station recorded an average annual rainfall of $841.90 \mathrm{~mm}$, slightly less than the state average of $945.00 \mathrm{~mm}$. Tamil Nadu state receives most of its rainfall from North-East monsoon. Though the city receives its quantum from both the monsoon seasons, but maximum quantum of rainfall happens during North-East monsoon.

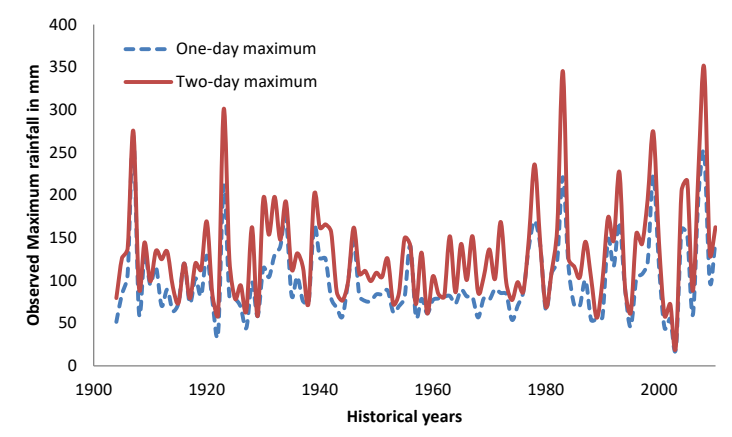

Fig.1. One-day and two-day observed maximum rainfall 


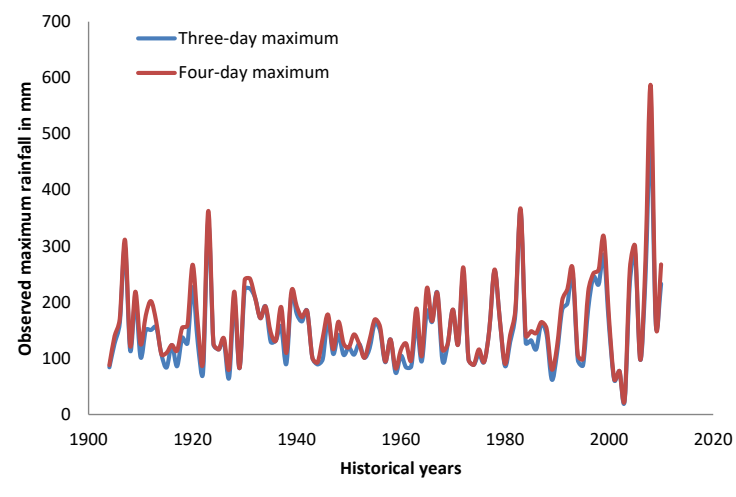

Fig. 2. Three-day and four-day observed maximum rainfall

\section{RESULTS AND DISCUSSION}

For the study area, one-day to five-day maximum rainfall for all the years of data was identified from year 1904 to 2010. In order to identify the 2-day to 5-day maximum rainfall, cumulative rainfall for varying number of days were worked out and maximum value in each year was utilized. Fig. 1 and 2 show the observed maximum one-, two-, three-, and four-day maximum rainfall over historical years. It can be seen from Fig. 1 that there is a significant difference in one-day and two-day maximum rainfalls, whereas for three-day and four-day, the difference is not that much apparent.

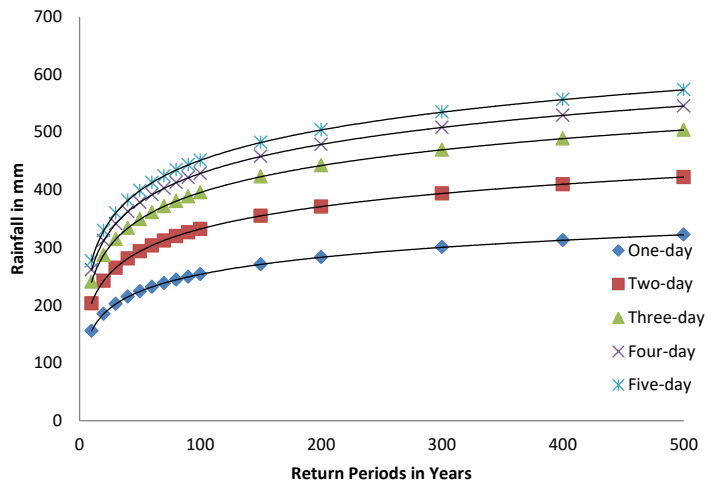

Fig. 3. Rainfall at different return periods according to Gumbel Distribution

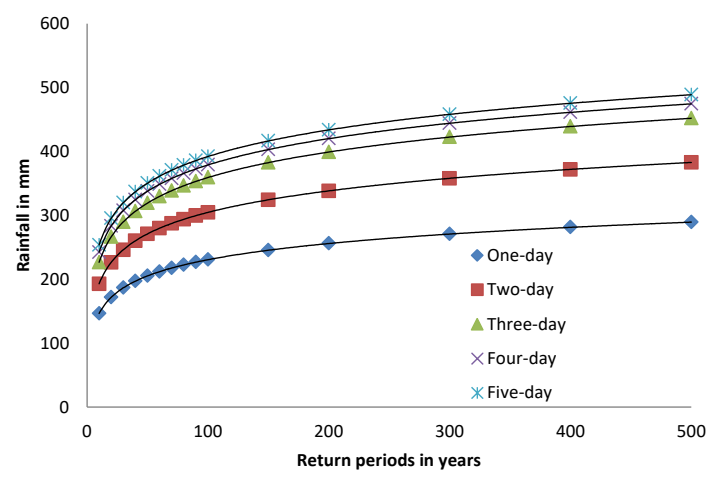

Fig.4 Rainfall at different return periods according to Gamma Distribution

This shows the importance of the rainfall in terms of hours or days need to be taken for consideration for different cases of hydrological design. Table 1 and 2 shows the maximum rainfall amount for 1-day to 5-day for different return periods by both methods. Comparison of these methods shows that the Gumbel distribution provided higher estimate than Gamma

distribution. In order to select best probability distribution method, AIC and BIC estimators were used. The method with least value of AIC or BIC is considered best probability distribution. AIC and BIC value for one-day maximum rainfall were worked out. Its value for Gumbel distribution is 1091.4 and 1099.2 respectively and in case of Gamma distribution, its value found to be 1094.016 and 1101.80 respectively. As there is no significant difference between these two distributions for this rainfall data, both the approaches can be utilized for finding maximum rainfall amount for various return periods. Fig. 3 and 4 show the variation of rainfall at different return periods by Gumbel and Gamma distributions respectively. It can be seen from the plot that rainfall at higher level of return periods shows marginal variations.

\section{CONCLUSION}

Two well-known probability distributions were fitted for maximum one-day to five-day rainfall of Tiruchirappalli station. According to AIC and BIC estimators, Gumbel and Gamma distributions fits well and rainfall amount for various return periods can easily obtained using these two distributions. And it can be used for urban water resources planning and management also for storm water drain design and its related structures. According to these two distributions rainfall at different return periods by Gumbel method gives higher estimate than Gamma distribution though there is no significant difference between the values of AICs and BICs. Considering the risk involved in the operation and management of hydraulic structures, rainfall at various return periods correspond to Gumbel method may be considered. Gamma distribution will be appropriate method in case for economical design of hydraulic structure with little risk involvement.

Table- I: Rainfall amount for different return periods by Gumbel distribution

\begin{tabular}{|l|r|r|r|r|r|l|l|}
\hline $\begin{array}{l}\text { Rainfall } \\
\text { Return } \\
\text { periods }\end{array}$ & 10 years & 20 years & 30 years & 50 years & 75 years & $\begin{array}{l}100 \\
\text { years }\end{array}$ & $\begin{array}{l}200 \\
\text { years }\end{array}$ \\
\hline One-day & 155.6 & 185.2 & 202.4 & 224.2 & 241.5 & 253.7 & 283.3 \\
\hline Two-day & 203.8 & 242.5 & 265.2 & 293.7 & 316.4 & 332.5 & 371.1 \\
\hline Three-day & 240.7 & 287.3 & 314.6 & 349.0 & 376.3 & 395.6 & 442.3 \\
\hline Four-day & 261.5 & 311.8 & 341.2 & 378.3 & 407.7 & 428.6 & 478.9 \\
\hline Five-day & 276.7 & 329.2 & 360.0 & 398.8 & 429.5 & 451.4 & 503.9 \\
\hline
\end{tabular}

Table- II: Rainfall amount for different return periods by Gamma distribution

\begin{tabular}{|l|l|l|l|l|l|l|l|}
\hline $\begin{array}{l}\text { Rainfall / Return } \\
\text { periods }\end{array}$ & $\begin{array}{l}10 \\
\text { years }\end{array}$ & $\begin{array}{l}20 \\
\text { years }\end{array}$ & $\begin{array}{l}30 \\
\text { years }\end{array}$ & $\begin{array}{l}50 \\
\text { years }\end{array}$ & $\begin{array}{l}75 \\
\text { years }\end{array}$ & $\begin{array}{l}100 \\
\text { years }\end{array}$ & $\begin{array}{l}200 \\
\text { years }\end{array}$ \\
\hline One-day & 146.5 & 171.8 & 186.6 & 205.3 & 220.1 & 230.6 & 255.9 \\
\hline Two-day & 192.9 & 226.5 & 246.2 & 271.0 & 290.7 & 304.6 & 338.3 \\
\hline Three-day & 226.4 & 266.4 & 289.8 & 319.2 & 342.5 & 359.1 & 399.1 \\
\hline Four-day & 242.1 & 283.3 & 307.3 & 337.7 & 361.7 & 378.8 & 419.9 \\
\hline Five-day & 253.6 & 295.2 & 319.6 & 350.3 & 374.7 & 391.9 & 433.6 \\
\hline
\end{tabular}




\section{REFERENCES}

1. V.T. Chow, D.R. Maidment, and L.W. Mays, (1988). Applied Hydrology, McGraw-Hill, New York, NY.

2. B. Bobee, and F. Ashkar (1991). "The Gamma Family and Derived Distribution Applied in Hydrology", Water Resources Publications, Littleton. CO.

3. R.H. McCuen, (1993). Microcomputer Applications in Statistical Hydrology, Prentice Hall. Englewood Cliffs, NJ.

4. J.R. Stedinger, R.M. Vogel, and E. Foufoule-Georgious, (1993) Frequency Analysis of Extreme Events in "Handbook of Hydrology", ed. D.R. Maidment, McGraw -Hill, New York, NY. Pp. 18.1-18.66.

5. P. Guhathakurta, M. Preetha, A.B. Mazumdar, O.P. Sreejith, (2010) Change in extreme rainfall events and flood risk in India during last century National climate centre, Indian meteorological department, Pune, India, Research report no. 3/2010.

6. S. Khan, G. Kuhn, A.R. Ganguly, D.J. Erickson, G. Ostrouchov, (2007) Spatio-temporal variability of daily and weekly precipitation extremes in South America. Water Resour Res 43(W11424):1-25.

7. E.J. Gumbel, (1942), On the frequency distribution of extreme values in meteorological data, Bull. Am. Meteorol. Soc., 23, 95-104

8. D. Koutsoyiannis, (2004), On the appropriateness of the Gumbel distribution for modeling extreme rainfall, in Hydrological Risk: Recent Advances in Peak River Flow Modelling, Prediction and Real-time Forecasting. Assessment of the Impacts of Land use and Climate Changes, edited by A. Brath, A. Montanari, and E. Toth, pp. 303-319, Editoriale Bios, Castrolibero, Bologna, Italy.

9. D.S. Wilks, (1993), Comparison of three-parameter probability distributions for representing annual extreme and partial duration precipitation series, Water Resour. Res., 29(10), 3543-3549

10. R.D. Markovic, (1965). Probability functions of best fit distribution of annual precipitation and runoff. Hydro-paper 8. Colorado State University, Colorado, USA.

11. Sheng Yue, (2000) "The Gumbel Mixed Model Applied to Storm Frequency Analysis” Water Resources Management 14: 377-389.

12. A. Bulu, and H. Aksoy, (1998) Low Flow and Drought Studies in Turkey, Proc. Low Flows Expert Meeting, 10-12 June 1998, University of Belgrade, Belgrade.

13. V.M. Yevjevich, (1972). Stochastic processes in hydrology, Water Resources publications.Fort Collins, Colorado.

14. Z. Sen, and A.G. Eljadid, (1999) "Rainfall Distribution Function for Libya and Rainfall Prediction", Hydrol. Sci. J., 44(5), 665-680.

15. H.C. Thom, (1958). A note on the gamma distribution. Monthly Weather Review 86: 117122.

16. D.S. Wilks, (1995). Statistical Methods in the Atmospheric Sciences: an Introduction. Academic Press: San Diego, CA.

\section{AUTHORS PROFILE}

Dr. K. Sasireka graduated from National Institute of Technology, Trichy and she completed her Ph.D. in the year 2017 from SASTRA Deemed Univeristy, Thanjavur, India. She is working as an Assistant Professor at School of Civil Engineering, SASTRA Deemed University from 2010. She works in the area of water resources management. She has more than 10 publication in reputed journals.

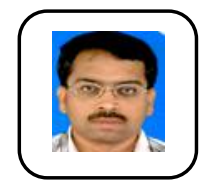

Dr. C.R. Suribabu is working as Professor at School of Civil Engineering, SASTRA Deemed University from 1998. He was awarded Ph.D. in the year 2006 from his research in hydraulic engineering from SASTRA Deemed University. He has more than 50 publications in reputed journals. He has handled many projects funded by

Government and private bodies.

Dr. T.R. Neelakantan is a Senior Professor in Civil Engineering and Director - Accreditation and Ranking at Kalasalingam Academy of Research and Education, Tamilnadu. He obtained his Ph.D. degree in Civil Engineering from Anna University in the year 1998. His working experiences are from Anna University, IIT-Madras, SASTRA Deemed University and the University of Kentucky, Lexington, USA. He published more than 60 articles in reputed journals, and handled many government and private funded projects both in India and USA. 